\title{
7
}

\section{Exceptionalism and Evasion: How Scholars Reason About Air Travel}

\section{Elina Eriksson, Maria Wolrath Söderberg, and Nina Wormbs}

To meet the $1.5^{\circ} \mathrm{C}$ target of the 2015 Paris agreement, we need both structural and individual change. This entails cutting our carbon emissions by 50 per cent every decade, starting in 2020 (Rockström et al., 2017). Individuals are key to societal change. At least three-quarters of global emissions are linked to individual or household activities (Druckman \& Jackson, 2016). This does not mean that change is easy; individual agency is, of course, limited by societal structures and culture. In addition, remaining emissions occur on system level, which means that individual steps will not suffice. At the same time, individuals are key to systemic and political change, by forming social movements and expressing their democratic rights (Burstein, 2003; Centola et al., 2018;

\footnotetext{
E. Eriksson $(\bowtie) \bullet N$. Wormbs

KTH Royal Institute of Technology, Stockholm, Sweden

e-mail: elina@kth.se; nina.wormbs@abe.kth.se

M. W. Söderberg

Södertörn University, Stockholm, Sweden

e-mail: maria.wolrath-soderberg@sh.se 
Chenoweth \& Stephan, 2011; Wolf \& Moser, 2011). Moreover, individuals are not just citizens but also, for example, politicians, business leaders, entrepreneurs, influencers and academic scholars. In this chapter, we are interested in how academic scholars reason when it comes to their own footprints, particularly in relation to flying, and to understand what they perceive would enable change.

Many scholars cause high greenhouse gas emissions by flying (Arsenault et al., 2019; Spinellis \& Louridas, 2013; Naturvårdsverket, 2019). As professionals and representatives of a particular group, they can be seen as having a specific responsibility regarding their own footprint from flying, since knowledge is their vocation (Spinellis \& Louridas, 2013). We know that awareness of climate change alone is not enough to prompt behavioural change (Moser \& Dilling, 2011; Norgaard, 2011). However, recent research has shown that knowledge is still important for change (Wolrath Söderberg \& Wormbs, 2019; Wormbs \& Wolrath Söderberg, 2021; Jacobson et al., 2020). The individual's ability to make an informed decision is often taken for granted in a liberal market economy dominating much of the Western world. We are interested in if and how that responsibility is framed and understood. We argue that to change organisations staffed to such a high degree by autonomous employees-true for most university and research organisations - it is imperative to understand the values and motives of these people.

This study is based on 556 free-text responses to one particular question in a survey about travelling habits at KTH Royal Institute of Technology in Stockholm. The question was 'A large part of the emissions at KTH come from air travel. What do you think should be done to reduce those emissions?.' We have used the rhetorical method of topos analysis to discern the lines of reasoning in the responses. By doing so we can capture values and motives, which can help us understand what kinds of discourse enable a transition to a sustainable society, and conversely, what kinds of discourses uphold inertia. 


\section{Background}

Climate change is a super wicked problem laden with goal conflicts. Moreover, there is no central authority we can turn to for a solution, and those we do turn to for solutions are also part of the problem (Levin et al., 2012). Hence, the fact that society turns to academy for solutions to contemporary problems is one reason to look at academics and analyse their views and values as they apply to their own footprints. Furthermore, among academics, there are not just people with arguably a high level of general knowledge but also those who for example study climate change, analyse the international and national governance systems for climate change mitigation, calculate costs of mitigation and non-mitigation and specialise in finding new engineering solutions.

The travelling scientist embodies a moral dilemma: We know we should not fly, but academic structures around us increasingly promote mobility (Storme et al., 2017; Lassen, 2009; Hopkins et al., 2019; Leung, 2013; Nursey-Bray et al., 2019), just as in Western society as a whole. There is a paradigm of mobility in academia. However, contemporary knowledge production is a historically constructed system with several parts. One is the dominating idea of internationalisation which permeates contemporary scholarship and is taken as a quality parameter in itself.

There is reason to believe that internationalisation leads to higher quality (Sugimoto et al., 2017), and cross-national knowledge exchange is a practise that predates 'the Great Acceleration' (Steffen et al., 2015; Crawford et al., 1992). The problem with internationalisation in recent decades is its conflation with mobility (see Ackers, 2008; Hoffman, 2009) — a conflation made by Sugimoto et al. (2017), among others. On the one hand, it has been shown that there are no clear links between mobility and quality (Aksnes et al., 2013; Wynes et al., 2019). On the other hand, mobility does not necessarily result in internationalisation. Thus, mobility is neither a necessary nor a sufficient condition for internationalisation.

One reason for scholars to engage in climate-related behavioural change is that knowledge itself yields power and demands responsibility. This has been argued by Higham and Font (2020), specifically in regard 
to flying and emission awareness. This position is ethical and pragmatic: If scholars act against their knowledge, they risk undermining their own message (Westlake, 2017; Oreskes, 2013; Attari et al., 2016). In fact, the effect of not practising what you preach has a considerable impact on the audience's inclination to support your policy, whereas a change in behaviour can mitigate this tendency (Attari et al., 2019). Furthermore, scholars and academics belong to a societal elite, with great resources and an enviable lifestyle, and their values and habits potentially influence others. All these perspectives also entail moral challenges.

We believe it is important to discern and analyse how scholars reason in this field of tension between knowledge and action, as it enables discussion and problematisation of assumptions, habits and norms.

\section{Method and Context of Study}

The so-called knowledge-action gap has been widely studied and analysed (Kollmuss \& Agyeman, 2002; Moser \& Dilling, 2007). The phenomenon has been noted in many different groups and contexts. Related to our study is a study by Lassen (2010), showing that knowledge workers, who consider themselves as environmentally aware, made no connection between their environmental attitude and their actual travel behaviour. It was possible for them to continue with high emissions despite deep knowledge and conviction of the climate crisis. Even more noteworthy is a study by Whitmarsh et al. (2020) showing similar results when it comes to climate scholars in regard to aviation. This study finds that the researchers with the most knowledge of climate change, namely professors with a focus on this specific issue, actually fly more than other researchers (Whitmarsh et al., 2020). Caset et al. (2018) calls this academic mobility a 'paradox', 'a blind spot' and an 'elephant in the room' needing to be addressed and calling for a shift in culture.

In the past decade, a series of models purporting to explain the knowledge-action gap have been put forward (Gifford, 2011; Stoknes, 2015; Kahan, 2014). Common for many of these is the critique of the information deficit model, the idea that knowledge leads to adequate action and that harmful climate behaviour, therefore, should be 
countered with more information. The critique states that more knowledge alone does not help (Norgaard, 2011; Moser \& Dilling, 2011).

In a study of Swedes that quit flying for climate reasons, we found, that contrary to existing theory, knowledge was actually mentioned by the respondents as an important factor in the behavioural change process (Wolrath Söderberg \& Wormbs, 2019; Wormbs \& Wolrath Söderberg, 2021). However, what the respondents described was specific forms of knowledge, such as the acuteness of the climate crisis, combined with insights about size and proportions of their own emissions, but also a wider concept of knowledge. They also described a climate experience, like drought or fire, or an existential one, like having a child. This seemed to transform the passive abstract knowledge into something concrete which allowed action (Wolrath Söderberg \& Wormbs, 2019). In another study, on the other hand, we found that Swedes who were inclined to live climate-friendly still failed on numerous occasions, and often, their subsequent justifications were built on misconceptions and lack of correct information (Wolrath Söderberg \& Wormbs, submitted). Hence, despite the above-discussed stance arguing that knowledge is not sufficient, we have found knowledge to be central. Thus, we wanted to investigate the reasoning of scholars, who arguably have knowledge as their vocation. Like in the two studies referred to here, our method has been topos analysis by which we can get hold of the thought structures of these scholars (Wolrath Söderberg \& Wormbs, 2019; Wormbs \& Wolrath Söderberg 2021; Wolrath Söderberg, 2017; Žagar, 2010; Rubinelli, 2009).

Our key question, then, is how scholars within academia reason around academic flying. To investigate this, we analysed a large sample of opentext answers in a travel survey (CERO travel survey) at KTH Royal Institute of Technology (KTH), distributed in the spring of 2019. KTH is a research-intensive technical university, which decided early on to become leading in sustainable development (KTHs Policy För Hållbar Utveckling, 2019). This programme spans education, research and collaboration with society, with the aim of mitigating climate change and working towards a sustainable society. The long-standing effort supports our hypotheses that scholars at KTH should possess knowledge on climate change and the means for a transition to a sustainable society. (The issue of academic flying was discussed at KTH already in 2014, in a series 
of seminars led by Johan Gärdebo and funded by KTH's Sustainability Office. Those seminars resulted in a booklet, and there was also a corresponding blog (Gärdebo et al., 2017).) However, in 2018, KTH was in fourth place among the state-funded authorities that had the largest emissions caused by long-haul flights (Naturvårdsverket, 2019).

Recently KTH has set climate targets for 2020-2045 broadly in line with the carbon law (Rockström et al., 2017), stipulating halving the carbon emissions every decade. As part of this work, emissions from travel are monitored through the CERO process (Robèrt, 2009). CERO stands for Climate and Economic Research in Organizations and is a framework for organizations to reach climate targets related to travel. The process includes commuting and business travel, even though commuting contributes with only a small share of carbon emission at KTH (7 per cent reported in 2019). Furthermore, the largest culprit within business travel (boat, car, rail, air) is air travel, which stands for 99 per cent of the carbon emissions from business travel.

In 2019, a new question was added to the CERO travel survey, in order to monitor how the employees at KTH reasoned about this large source of emissions. The question was: 'A large part of the emissions at KTH come from air travel. What do you think should be done to reduce those emissions?.' It was posed on the first page of the five-page web survey. The entire survey received 1418 responses. We have analysed the 556 responses submitted to this question by faculty (teachers and researchers) and $\mathrm{PhD}$ students at the university. We excluded answers from technical and administrative staff since we are interested in how academics reason about their own flying, as they are responsible for the majority of the emissions from flying. These answers make up the empirical material for this chapter. Some results from the CERO survey have been published in Eriksson et al. (2020), but then only the answers from the school of Electrical Engineering and Computer Science (one of five schools at $\mathrm{KTH}$ ), and looking at all free-text responses in the survey.

Generally, the coding was inductive and open. However, we also had certain hypotheses that we wanted to investigate. As indicated earlier, we expected the responses to take into account that academics are role models. We hypothesised that people in this sample have the knowledge required for making informed choices and that we would not find the 
same kind of misunderstandings in this material as in a more general sample. We also expected an elaborate argument for evading responsibility in the cases when this was called for. This would be in line with earlier observations of the prevalent types of justifications for avoiding changing behaviour and overcoming cognitive dissonance (Festinger, 1957). Moreover, we expected some exceptionalist arguments, as we have found that in another study (Wolrath Söderberg \& Wormbs, submitted). And finally, we believed that there was a social pressure of going to conferences-an expectation of travelling.

We use the terms scholar and academic in this chapter since the sample consists of PhD students, researchers and faculty at KTH Royal Institute of Technology as a whole. However, we do not know the precise discipline of the respondents, since KTH has a wide variety of research. The research and training span questions that engage deeply with sustainability and climate from the view of the humanities and social sciences to engineering and natural science, but in some cases have no connection to sustainability and climate issues whatsoever. It is impossible to draw a disciplinary line here as, say, civil engineering or computer science can include issues of sustainability but will not necessarily do so. We know with a high level of certainty that the sample contains a majority of responses from the engineering sciences and natural science since the humanities and social sciences are sparsely represented at $\mathrm{KTH}$, but we cannot methodologically separate answers from different disciplines.

\section{Findings: Specific Solutions and General Inertia}

A first important finding is that also among scholars at Sweden's largest technical university, the question on what should be done to lower emissions - a politically decided aim — can be dismissed as unwarranted, and a few responses actually deny that climate change exists. There are also a few who might concede to climate change, but still deny. (While our data set is not statistically produced, we can see that the percentage of denialist answers are approximately the same as that of the population as a whole. More research is needed to say anything more general on denialism at $\mathrm{KTH}$. The number of responses refusing action in an articulate way is 
low but noteworthy). The majority of the responses accept the validity of the question posed, but relate very differently to it. As our analysis will show their ways of engaging with the issue fall into two categories: suggestions to change and arguments of inertia. This division is theoretically important as they turn out to be different rhetorically: in the first category we find concrete, situated proposals, and in the second we find timeless and common types of argument of the kind that already Aristotle highlighted as general topoi. Central to categories is the way in which agency is understood.

\section{Suggestions to Change}

There are nine discernible suggestions for action which are also often concrete and specific. They are, in order of frequency, with the most commonly inferred first: to change old or establish new habits; to limit or enable; to use or change technology; to carbon offset; to change the system or the structure; to inform and visualise; to use a less harmful solution; to pay attention to the social dimensions; and, finally, to move into a transformative mode.

The large majority of the responses deal with habits, limiting or enabling and technology. To change old or establish new habits often refers to the general need of flying less, travelling more by train and exchanging mobility with digital meetings. The answers often lack a clear agent (they are written in a passive voice without a subject) and mostly only one practice is mentioned per free-text answer. An example of a passive statement, but with several suggestions, is the following quote: 'Opt for train-based travel when possible, reduce the amount of contact meetings in general and perform more digital based meetings'. Likewise belonging to this type of suggestions are encouraging and discouraging efforts, also with an unclear agent and often to achieve marginal change. Some suggest that committee members for recruitment, promotion or $\mathrm{PhD}$ defences should not be flown to Sweden but allowed to participate at a distance.

When it comes to limiting or enabling, many responses argue that directives and policies should be put in place. These might have to be harsher, more specific and more detailed than today. Specific ideas 
suggest the train as a first option, even if it is more expensive than flying, and that flying should not be possible for short distances. Flying should be motivated and approved by the Head of Department (approval is a practice already in place for all business travel but apparently without impact for reducing emissions from flying according to this respondent). Some suggest a ban on national or short-distance flying, or on 'unnecessary' flying, or that fewer trips should be allowed and that the distance should be reflected in the time spent on site. It is common to argue for limiting the number of trips. Ideas vary from limiting per-person trips, reducing the number of legs on a specific trip, to reducing the number of people travelling to the same conference. A carbon budget is frequently brought forward, resonating well with the public discourse. This budget can be personal or per department or another organisational unit. That external funding bodies should make demands in this vein is also suggested, contrary to the situation today where extensive travelling is often expected. A related suggestion based on an argument of direction is to start with limiting the greatest emitters, as in the following quote: 'Some people are in the US or in Asia once a month. Begin with those who give rise to the largest emissions.' To enable change by offering alternatives is a very common suggestion where agency is with the institution itself. On the one hand, digital meetings should be easy and of high quality and, on the other hand, booking train trips should be less cumbersome.

A large portion believes very strongly that specific or unspecific economic incentives of different kinds can limit or enable. Reward in some form is mentioned among the explicit suggestions, like more research time, higher salary, more vacation, first-class travel and meals. To exchange a trip for a digital meeting could also be rewarded. Very few suggest punishments for flying, but the mirror image to reward-internal 'taxation'-is common. This tax can be used by those who travel more sustainably; it can be progressive, that is if you travel a lot it becomes higher (this corresponds to an already existing internal taxation at KTH with limited impact, but it is hard to know if the respondents know about this system).

Another specific suggestion deals with technology. A few responses concern the need for development of the technologies for digital meetings. The major part, however, is about the technology of aviation. Here the 
main argument is that KTH (or unspecified others) should develop sustainable airplanes or sustainable fuels. Within this category, some suggest that KTH should be an agent in this development, but some are vague regarding who or where this should be done. Some think far ahead: electric planes or 'small nuclear reactors that cannot meltdown and develop the thorium-mixed fuel which does not leave radioactive waste'.

In relation to changing technology, there is an idea in some responses that those who work towards new solutions might be offered the possibility to travel more for that particular reason; scientists have to fly, and for that reason airplanes need to become more sustainable. This can be regarded as an exceptionalist argument. Exceptionalist here means the idea that different rules should apply to scholars given their special function. In the material, there is also another argument connected to exceptionalism, namely the idea that scholars are more entitled to fly than for example administrative staff, since scholars teach or research-the main tasks at a university.

The responses demanding or suggesting better aviation technology have in common that they do not require refraining from flying. This also applies to suggestions about carbon offsetting. The suggestion is that KTH compensates for the employees' travel. This way of reasoning is akin to the already mentioned idea that KTH should introduce a local form of climate compensation where those who fly pay a fee that can then be used to finance more expensive rail journeys. This suggestion, however, entails that the 'taxation' of the price tag for flights and the lower price for railway journeys would lead to other choices. Carbon offsetting, on the other hand, can be interpreted as a way to buy oneself free. Some suggest that a fee for carbon offsetting should be included directly in the ticket price and some that KTH should compensate for the climate 'more than in full'. There are also other examples of compensatory ideas, such as planting trees or 'investing in research projects in sustainable energy' or burying biochar. Someone suggests compensating by 'buying/promoting goods and services from local businesses/manufacturers/growers with lower carbon footprint'. Other answers point to small changes away from flying; one suggests turning off computers at night. In many of these responses, questionable suppositions are made about how carbon offsetting works and about proportions of different climate-harming actions. 
A related way of reasoning is to suggest a less harmful way to continue flying. Many highlight biofuels. Some suggest fewer stopovers, to choose more fuel-efficient flights or to fly during the day.

Suggestions to change the system or the infrastructure often include improvement of the railroad or air traffic, with an emphasis on the former. Faster trains, more connections, improved booking systems and generally better trains that can also house meeting rooms are among the ideas.

There are a few responses which point to a need for increased knowledge about the detrimental environmental and climate impact of flying. These suggestions focus on the need to inform and visualise. It should be easy to make informed decisions about which choices result in what emissions. Some also suggest that emissions rather than price should be the sorting function and that emissions should be visible on travel documents. To continuously monitor travelling would be yet another way to increase information and make employees aware of their own travel. This, in turn, makes travelling a matter of personal responsibility. There are also suggestions to make this visible on a higher institutional level and to make different units compete with each other.

Paying attention to the social dimensions is suggested in a few responses. They reveal existing norms and expectations about mobility. Some point to established practices of conference travel, some regard it a benefit or criticise habits of going to conferences for fun, but the possibility to act as a role model is also mentioned. This can be enacted not just by refraining from travel, but also by arranging web-based meetings. One respondent connects the periphery of Sweden with the possibility to alter the norm: 'To instead be a role model to the World on how to organise meetings would give us leverage by being more inclusive and allowing for people on parental leave or researchers with limited resources to participate'. When analysing the material, we found it striking that these social responses are so few and that the pressure or expectations mostly seems to be (perceived as) on a structural level rather than an explicit peer level. However, it can also be forcefully argued that travelling is such an intrinsic part of academic activity and thus deeply cultural and therefore no social pressure is needed. Regarding peer pressure, we see a couple of suggestions about public shaming, aimed at displaying the emissions of 
individuals or groups, which would enable comparison within the organisation.

The last dimension deals with transformation and is also scarce. It includes ideas of system change on a more radical level, like zero growth or even de-growth, as the present market economy is viewed as the underlying problem.

Among these nine specific suggestions, we found that it is possible to discern a spectrum of measures, ranging from slow and non-invasive, to forceful and drastic. The least invasive is to develop new technology and, implicitly, carry on as before. Compensating for $\mathrm{CO}_{2}$ emissions is very closely related and can be viewed as a kind of 'fix'. To work with changing the structure of the academic system is more forceful but removes responsibility from the individual and will take time. Using less harmful solutions is also non-invasive and demands little. To inform and visualise places all responsibility on the individual and is voluntary. Similar are efforts to try and establish new habits, which are voluntary. To enable, is an offer and thus not compulsory, but expected to foster behavioural change. Limiting, on the other hand, is drastic and forces change. At the far end of the spectrum, we can find ideas of a total transformation of the economic system. We find this as a slight paradox, since this suggestion of total transformation actually would relieve the individual from action and thus might be placed in the non-committal end of this spectrum.

\section{Arguments of Inertia}

Among the responses accepting the question and suggesting solutions, there are some very modest and somewhat passive proposals pointing to the responsibility of others. However, in the material, there are also many free-text answers that more actively motivate passivity in different ways. The common denominator in most of those answers is that they are grounded in timeless and general rhetorical topoi, already recorded by Aristotle (Aristotle, 1991; Wolrath Söderberg, 2017; Perelman \& Olbrechts-Tyteca, 1969). These topoi are the possible, the necessary, the reality, the good cause and the special. At first, we were surprised to find this, but on second thought, it made perfect sense, and we should have 
expected it. These topoi are indeed timeless, very common and already identified in Aristotle's Rhetoric, as we will discuss further.

The possible is invoked as an excuse for not lowering emission based on the idea that it should only be done 'when possible'. Akin to possible is - striving towards, trying, if reasonable, if there are good alternatives, if affordable and so on. All offer a way out of commitment and are in general evasive and non-precise, exemplified in the following quote: 'If possible, use alternative modes of travel, if it is practicably feasible. For example, train to Stockholm and Lund.'

The necessary is more explicit. Sometimes a definitive necessity to fly is claimed, but more often an implicit distinction is made between necessary and unnecessary travel, even though what is unnecessary seems very hard to define. One effort has to do with the primary tasks for the university, namely research and training. For research, flying is seen as necessary, but not for teaching, or even worse, administrative meetings. In this thought structure, the exceptionalism of scholarly activities is visible in wordings like 'research demands international meetings and networks'. It is presented as a fact. A related idea is travelling as a reality. In 'reality', scholarly life demands flying, and it is hopeless to negotiate with reality.

To argue that flying is for a good cause puts the emission in relation to an expected achievement. Depending on the reason for undertaking the trip, it can be justified, and in particular, if the trip is useful, an example of time-well-spent. To solve environmental problems holds a special position in this regard, as in the following quote: 'Prioritize what is most important. Some should travel more if it concerns establishing research cooperation, for example with European partners, if the research aims at improving environmental issues.' The mirror image of the good travel is the unnecessary travel, which is stated to be going on in other parts of the university.

As mentioned earlier, an exceptionalist topos is visible in the material. Either academia or science is special and therefore entitled to fly. Scientists need to network and cooperate, and this might even contribute to solving the problem. There are also special considerations to be made of another kind: KTH has special conditions since Stockholm is at the margin of Europe and therefore far away. One related example is the argument that 
Sweden has a lot of forests which function as coal sinks, which is assumed to justify that we should have a special right to fly.

These topoi are based on very general, self-evident ideas about valuesthe possible is to prioritise before the impossible, the necessary before the unnecessary, that with a good cause before that with no or a bad cause, and the special which motivates certain benefits or exceptions. This way of reasoning is also an example of a topos itself, namely dissociation, where opposition is created through division.

There are also general topoi of another kind, but rather based on common thinking operations. The most prevalent is pointing at goal conflicts. Values such as the personal meeting, collaboration, efficiency, merit and impact are raised as arguments for proceeding with current flying habits. These responses point out that increased participation in EU projects, expectations of visibility at conferences and exchanges of people with other universities in Sweden and abroad are in direct opposition to decreasing travelling. Management must be clearer about which goals to prioritise.

We found it interesting that all these topoi are used in an evasive way, legitimising non-action and inertia. It could have been possible to infer the necessary, for example, in relation to the necessity to change habits and stop emitting. It could have been argued that lowering emissions is indeed a good cause, or that climate change is a reality that you cannot argue with. And finally, to underscore that change is possible might have been a response in the face of the very high emission numbers of the university. Instead of allowing for change, possible turned out to be an argument that is a hindrance to change. This points to the central question of ownership of action, namely agency.

\section{Agency}

A central dimension in the empirical material has to do with agency in regard to the suggested measures, and where it is placed. The most common place to put agency is on the institutional level, the university as such. Often the agent is not pinpointed but invoked rather than explicitly articulated. There are exceptions to this, like when the argument has 
to do with digital solutions where the IT department can be called upon or travel bookings, where the travel agency can be held responsible. In general, however, also when very concrete ideas that have to do with regulating, stimulating, redistributing, budget and so on are suggested, the agency lies with the university as an institution, without pinpointing which part of the organisation that should take action. The academic system or culture as such also has agency in relation to emissions, but is seldom articulated as such. Here too, agency is implicit.

There are instances of agency placed on oneself or a collective, but very few responses use the first person-I. Only a few use themselves as an example: 'I have reduced my travel significantly, and only go to a few high-priority conferences'. In fact, there is overall a surprising lack of concreteness in regard to agency. To some extent, this is expected since the initial question was general and passive and there was no specific question of where agency should be placed. Still, it could have been possible to respond with a higher level of specificity than many of the answers display. It should be noted that there can be a systematic bias here in that natural scientists and engineers (the majority of the respondents) are trained in expressing themselves passively and not use the first person, neither in singular nor in plural.

Finally, a number of responses refer to a named or unnamed 'someone else'. In a few instances, it is hard to discern if the reference to the institution is also a someone else, or if the respondent includes him or herself into that category. This can, at times, be conflated with the abovementioned implicit I/we/KTH. Some responses point to the responsibility of the president who should be a role model, administrative staff who should fly less or someone outside of KTH (the political system or the culture in society) who should fix technology or infrastructure.

Agency, in our interpretation here, is seldom specified and mostly lies with someone else. This can be explained by the nature of the initial question but is still noteworthy. 


\section{Discussion}

On an overarching level, the answers fall into two groups: one rejecting and one accepting the proposal to lower emissions. In the first group, there are those denying climate change altogether, containing a handful of answers and a few that might accept climate change but reject the proposal that KTH should lower emissions. In the other group, comprising the vast majority, there are those who take issue with the proposal in an elaborate way and those who give suggestions to solve the issue. The overlap between these two large groups is not great, although there is a small overlap. Hence, the tension between these seemingly contradictory arguments is thus not within individuals, but between groups.

One of the reasons to look at this sample of academics was our interest in how knowledge functioned in arguments around lowering emissions. Our hypothesis was that we would not find the same kind of misunderstandings in this material as we have in previous research. We did find some responses that show misconceptions about sizes or proportions of emissions. For example, the poor understanding of how carbon offsetting works among those who have suggested that a particular solution in this survey is noteworthy. Likewise, knowledge on possible technological solutions to fossil-driven airplanes also seems low among those few that invoke technical change. However, we can conclude that, in general, knowledge was higher in this sample than in previous research.

Interestingly enough, despite what can be interpreted as a high level of knowledge, this does not seem to enable action. As hypothesised, we found arguments for evading responsibility. However, they were not elaborate or specific as we hypothesised but rather clean and classic, referring to topoi identified already by Aristotle. This is an intriguing and interesting find, and meets with our hypothesis about exceptionalism. These arguments are relatively non-specific and general and call upon values and understandings of academics among the expected receiver of the survey. We are expected to be able to relate to the 'realities' of academic work that put demands on flying, that 'necessary' flying should be allowed and that it is indeed for a 'good cause' that scholars are so mobile. 
It is worth considering that the same topoi could have been used to argue for reducing flying: The necessary could have been necessary in relation to climate change; the real could have been invoked in relation to the reality of climate change; the good cause could have been the survival of species or the planet; the special could instead have been an argument for scientists as role models limiting impacts from emissions rather than claiming an exceptionalist role for scientists. Only the classical topoi of the possible is a structure that is not solely used to legitimise inertia in this material, even though it is mostly invoked in ways that allow for evasion.

We found the sheer volume of responses that placed the responsibility elsewhere striking. At the same time, this is a deeply human strategy for dealing with dissonances between preaching and practice and for refuting charges against one's own morality. The strategy of displacing responsibility was observed and conceptualised already in the rhetorical teaching of stasis developed by Hermagoras, Hermogenes, Cicero and others (Nadeau, 1959).

If we consider the rhetorical situation of the respondents, using stock arguments as a way of resisting, is rational and expected. The survey question was 'A large part of the emissions at KTH come from air travel. What do you think should be done to reduce those emissions?.' The question left no easy room for a negative answer, nor for a distinct counter position. Moreover, to protest was most likely perceived as socially unacceptable (although a few did). Furthermore, we can assume that the vast majority of respondents are well aware of the seriousness of the climate crisis and do not deny it. However, faced with a situation where habits and values are questioned, and behavioural change are unwelcome or difficult, referring to eternal and general arguments is rational. To be valid, these arguments must be recognised in the existing context of peers, as the necessity of mobility for research quality or the exceptionality of scholarly work. Since it was not possible to state that flying should continue, arguments instead had to be vague and general. In Aristotle's view, specific arguments are more persuasive, but if we lack access to specific arguments, we can have good use of general ones (Aristotle, 1991).

The large number of concrete suggestions and the seemingly strong support for interventions, regulations and incentive structures to lower emissions from flying are encouraging for someone who needs to find 
ways of lowering emissions at KTH. The suggestions about more forceful systemic solutions might have to do with a disbelief in individual agency. This might, in turn, be an ontological standpoint, but it can also have a practical and economic explanation. A lion part of research at KTH is externally funded by research agencies and foundations which grant money to individual scholars, who then dispose of travel money as part of the grant. Funding for mobility is thus not primarily allocated by the university, but made possible by external actors. Thus, a general decision to limit flying might be a forceful way in a context where individual autonomy and funding has been the rule.

We might have expected more answers that dealt with individual responsibility, but in light of the funding structure, the call for system change and general regulation can also be regarded as rational. This is another way of looking at agency. Placing of responsibility elsewhere can thus be interpreted as an evasive strategy, avoiding behavioural change, but it can, on the other hand, be rational given the existing funding context. Furthermore, it can be a starting point of dialogue for change. When stuck between cultural values, individual responsibility and organisational change, the responses can be interpreted as 'bids' in an emerging process of transformative change.

To suggest general solutions can also be a surprising find if we regard mobility as an academic right. However, the academic freedom argument does not appear anywhere in the responses. It might be explained by the fact that most believe that they will still be able to move around, although under different circumstances. On the other hand, if the management at KTH had decided to implement more regulations, internal taxations and so on, the reaction might have been different. Then we might have seen responses based on the idea of academic freedom.

One noteworthy find is the apparent lack of social pressure to fly, or not to fly in the responses. It can be argued that the question did not invite that kind of reflection and further research is important, particularly given the above-mentioned academic culture of mobility, which arguably means that you do not have to justify a trip. The external expectations that our respondents do refer to are not framed as social, but as systemic, constituting knowledge production. This is both important and interesting. If the expectations are perceived as inherent in the system or 
the role of the scholar, they are more likely to be seen as necessary and harder to work against. Without any discussion or social pressure to change this system, the individual is left alone. A possible interpretation is that understanding the pressure as systemic becomes an argument for the status quo. At the same time as there are few examples of more explicit remarks on social dimensions, a common identity is assumed in the exceptionalist perspective and in the topos of the necessary. In this empirical material, we only see few traces of collegial conversations about the problem of flying, which is explicitly expressed as a culture of silence in Eriksson et al. (2020) and could be perceived as a social construction of denial (Norgaard, 2011). There is reason to believe that initiatives that break the silence can be a fruitful way forward (Randall, 2009).

There are a few expected arguments which were more or less absent. For example, an interesting find is that the terms quality and internationalisation in relation to travel are lacking. The word quality shows up, but only on a few occasions and then in relation to either digital tools for distance meetings or the class of train travel and booking. The idea of a connection between quality and travel can nevertheless be perceived as implied in several of the free-text answers that emphasise the necessity of travel or the researcher or research as special. Again, the idea that this is part of a general understanding and does not need articulation must be considered. Internationalisation is also absent as an argument against reducing emissions, although it too might be understood as assumed in the reasoning about the necessity of flying. However, we need further research to be able to say more about how these expected core values interplay with reduced mobility.

\section{Conclusion}

This chapter has presented results from a qualitative analysis of free-text answers from a travel survey at KTH Royal Institute of Technology. The aim of the study was to understand how scholars within academia reason around flying, and about the need to lower emissions from flying. A key insight of this study is that there is substantial support for interventions in order to lower emissions from flying. The respondents also show 
ingenuity when suggesting different enabling strategies. University leadership should be able to take advantage of this, both when finding forms of implementation approved by employees and as a basis for justifying regulations, restrictions, internal tax and incentive structures.

Another major insight from the study concerns arguments of inertia, important to understand if you want to achieve transformation. This study shows that general topo $i$ are used as a way to evade responsibility. These general topoi call on implicit assumptions about the scholar's role and identity and assumptions about the academic system. This might stem from a genuine wish to evade the needed reductions in travel, or from a perceived lack of agency within the system. Either way, distinguishing these topoi opens up for designing dialogues with the potential for self-reflection.

The large number of vague answers, without clear agency, and the lack of social pressure in the free-text answers point to a silence around the issue of academic flying and its harmful carbon emissions. This could be interpreted as a social construction of denial. One way to break this barrier to action is to spur collegial conversations around the issue. To cite Donella Meadows, to change a paradigm, '[y] ou keep pointing at the anomalies and failures in the old paradigm. You keep speaking and acting, loudly and with assurance, from the new one' (Meadows, 2008, p. 164). This, however, needs to be done in an empathetic way, since it is often painful to reconsider what one takes for granted or have become attached to. If we do not interpret the arguments of inertia used by our respondents in this study as a lack of knowledge, nor a lack of interest, but rather a struggle within a system that is not yet supporting a shift to low carbon knowledge production, to talk about it is the most important thing we can do. To discern, articulate and display our underlying reasoning is a first step.

\section{References}

Ackers, L. (2008). Internationalisation, mobility and metrics: a new form of indirect discrimination? Minerva, 46(4), 411-435. 
Aksnes, D. W., Rørstad, K., Piro, F. N., \& Sivertsen, G. (2013). Are mobile researchers more productive and cited than non-mobile researchers? A largescale study of Norwegian scientists. Research Evaluation, 22(4), 215-223. https://doi.org/10.1093/reseval/rvt012

Aristotle. (1991). On rhetoric: A theory of civic discourse. Oxford University Press. Arsenault, J., Talbot, J., Boustani, L., Gonzalès, R., \& Manaugh, K. (2019). The environmental footprint of academic and student mobility in a large researchoriented university. Environmental Research Letters, 14(9), 095001.

Attari, S. Z., Krantz, D. H., \& Weber, E. U. (2016). Statements about climate researchers' carbon footprints affect their credibility and the impact of their advice. Climatic Change, 138(1), 325-338.

Attari, S. Z., Krantz, D. H., \& Weber, E. U. (2019). Climate change communicators' carbon footprints affect their audience's policy support. Climatic Change, 154(3), 529-545.

Burstein, P. (2003). The impact of public opinion on public policy: A review and an agenda. Political Research Quarterly, 56(1), 29-40.

Caset, F., Boussauw, K., \& Storme, T. (2018). Meet \& fly: Sustainable transport academics and the elephant in the room. Journal of Transport Geography, 70, 64-67. https://doi.org/10.1016/j.jtrangeo.2018.05.020

Centola, D., Becker, J., Brackbill, D., \& Baronchelli, A. (2018). Experimental evidence for tipping points in social convention. Science, 360(6393), 1116-1119. https://doi.org/10.1126/science.aas8827

Chenoweth, E., \& Stephan, M. J. (2011). Why civil resistance works: The strategic logic of nonviolent conflict. Columbia University Press.

Crawford, E., Shinn, T., \& Sörlin, S. (1992). Denationalizing science: The contexts of international scientific practice. Kluwer Academic Publishers.

Druckman, A., \& Jackson, T. (2016). Understanding households as drivers of carbon emissions. In R. Clift \& A. Druckman (Eds.), Taking stock of industrial ecology (pp. 181-203). Springer International Publishing.

Eriksson, E., Pargman, D., Robèrt, M., \& Laaksolahti, J. (2020). On the necessity of flying and of not flying: Exploring how computer scientists reason about academic travel. In Proceedings of the 7th International Conference on ICT for Sustainability (pp. 18-26). Association for Computing Machinery. https://doi.org/10.1145/3401335.3401582

Festinger, L. (1957). A theory of cognitive dissonance. Row, Peterson.

Gärdebo, J., Nilsson, D., \& Soldal, K. (2017). The travelling scientist: Reflections on aviated knowledge production in the Anthropocene. Resilience: A Journal 
of the Environmental Humanities, 5(1), 71-99. https://doi.org/10.5250/ resilience.5.1.0071

Gifford, R. (2011). The dragons of inaction: Psychological barriers that limit climate change mitigation and adaptation. The American Psychologist, 66(4), 290-302. https://doi.org/10.1037/a0023566

Higham, J., \& Font, X. (2020). Decarbonising academia: Confronting our climate hypocrisy. Journal of Sustainable Tourism, 28(1), 1-9. https://doi.org/1 0.1080/09669582.2019.1695132

Hoffman, D. M. (2009). Changing academic mobility patterns and international migration: What will academic mobility mean in the 21 st century? Journal of Studies in International Education, 13(3), 347-364. https://doi. org/10.1177/1028315308321374

Hopkins, D., Higham, J., Orchiston, C., \& Duncan, T. (2019). Practising academic mobilities: Bodies, networks and institutional rhythms. The Geographical Journal, 185(4), 472-484. https://doi.org/10.1111/geoj.12301 Jacobson, L., Åkerman, J., Giusti, M., \& Bhowmik, A. K. (2020). Tipping to staying on the ground: Internalized knowledge of climate change crucial for transformed air travel behavior. Sustainability, 12(5), 1994. https://doi. org/10.3390/su12051994

Kahan, D. M. (2014). Making climate science communication evidence based-All the way down. In D. A. Crow \& M. T. Boykoff (Eds.), Culture, politics and climate change: How information shapes our common future (pp. 203-220). Routledge.

Kollmuss, A., \& Agyeman, J. (2002). Mind the gap: Why do people act environmentally and what are the barriers to pro-environmental behavior? Environmental Education Research, 8(3), 239-260. https://doi. org/10.1080/13504620220145401

"KTHs Policy För Hållbar Utveckling." (Translation: KTH Policy for Sustaianble Development) (2019). KTH Royal Institute of Technology. V-2019-0451

Lassen, C. (2009). Networking, knowledge organizations and aeromobility. Geografiska Annaler: Series B, Human Geography, 91(3), 229-243. https://doi. org/10.1111/j.1468-0467.2009.00317.x

Lassen, C. (2010). Environmentalist in business class: An analysis of air travel and environmental attitude. Transport Reviews, 30(6), 733-751. https://doi. org/10.1080/01441641003736556

Leung, M. W. H. (2013). 'Read ten thousand books, walk ten thousand miles': Geographical mobility and capital accumulation among Chinese scholars. 
Transactions of the Institute of British Geographers, 38(2), 311-324. https:// doi.org/10.1111/j.1475-5661.2012.00526.x

Levin, K., Cashore, B., Bernstein, S., \& Auld, G. (2012). Overcoming the tragedy of super wicked problems: Constraining our future selves to ameliorate global climate change. Policy Sciences, 45(2), 123-152.

Meadows, D. H. (2008). Thinking in systems: A primer. Chelsea Green Publishing. Moser, S. C., \& Dilling, L. (2007). Creating a climate for change: Communicating climate change and facilitating social change. Cambridge University Press.

Moser, S. C., \& Dilling, L. (2011). Communicating climate change: Closing the science-action gap. In J. S. Dryzek \& R. B. Norgaard (Eds.), The Oxford handbook of climate change and society (pp. 161-174). Oxford University Press.

Nadeau, R. (1959). Classical systems of stases in Greek: Hermagoras to Hermogenes. Greek, Roman and Byzantine Studies, 2(1), 53-71.

Naturvårdsverket. (2019). Miljöledning i Staten 2018. Naturvårdsverket.

Norgaard, K. M. (2011). Living in denial: Climate change, emotions, and everyday life. MIT Press.

Nursey-Bray, M., Palmer, R., Meyer-Mclean, B., Wanner, T., \& Birzer, C. (2019). The fear of not flying: Achieving sustainable academic plane travel in higher education based on insights from South Australia. Sustainability, 11(9), 2694. https://doi.org/10.3390/su11092694

Oreskes, N. (2013, June 15). The scientist as sentinel. Limn. https://limn.it/ articles/the-scientist-as-sentinel/

Perelman, C., \& Olbrechts-Tyteca, L. (1969). The new rhetoric: A treatise on argumentation. University of Notre Dame Press.

Randall, R. (2009). Loss and climate change: The cost of parallel narratives. Ecopsychology, 1(3), 118-129. https://doi.org/10.1089/eco.2009.0034

Robèrt, M. (2009). A model for climate target-oriented planning and monitoring of corporate travel. International Journal of Sustainable Transportation, 3(1), 1-17. https://doi.org/10.1080/15568310701517752

Rockström, J., Gaffney, O., Rogelj, J., Meinshausen, M., Nakicenovic, N., \& Schellnhuber, H. J. (2017). A roadmap for rapid decarbonization. Science, 355(6331), 1269-1271. https://doi.org/10.1126/science.aah3443

Rubinelli, S. (2009). Ars topica: The classical technique of constructing arguments from Aristotle to Cicero. Springer Science \& Business Media.

Spinellis, D., \& Louridas, P. (2013). The carbon footprint of conference papers. PLoS ONE, 8(6), e66508. 
Steffen, W., Broadgate, W., Deutsch, L., Gaffney, O., \& Ludwig, C. (2015). The trajectory of the Anthropocene: The great acceleration. The Anthropocene Review, 2(1), 81-98. https://doi.org/10.1177/2053019614564785

Stoknes, P. E. (2015). What we think about when we try not to think about global warming: Toward a new psychology of climate action. Chelsea Green Publishing. Storme, T., Faulconbridge, J. R., Beaverstock, J. V., Derudder, B., \& Witlox, F. (2017). Mobility and professional networks in academia: An exploration of the obligations of presence. Mobilities, 12(3), 405-424. https://doi.org/1 0.1080/17450101.2015.1116884

Sugimoto, C. R., Robinson-Garcia, N., Murray, D. S., Yegros-Yegros, A., Costas, R., \& Larivière, V. (2017). Scientists have most impact when they're free to move. Nature News, 550(7674), 29.

Westlake, S. (2017). A counter-narrative to carbon supremacy: Do leaders who give up flying because of climate change influence the attitudes and behaviour of others? SSRN Scholarly Paper. ID 3283157. Rochester: Social Science Research Network.

Whitmarsh, L., Capstick, S., Moore, I., Köhler, J., \& Le Quéré, C. (2020). Use of aviation by climate change researchers: Structural influences, personal attitudes, and information provision. Global Environmental Change, 65, 102184. Wolf, J., \& Moser, S. C. (2011). Individual understandings, perceptions, and engagement with climate change: Insights from in-depth studies across the world. WIREs Climate Change, 2(4), 547-569. https://doi. org/10.1002/wcc. 120

Wolrath Söderberg, M. (2017). Aristoteles retoriska toposlära-En verktygsrepertoar för fronesis. Södertörn Rhetorical Studies.

Wolrath Söderberg, M., \& Wormbs, N. (2019). Grounded: Beyond flygskam. Fores.

Wolrath Söderberg, M., \& Wormbs, N. (submitted). Internal Deliberation Defending Climate-harmful Behavior. Argumentation.

Wormbs, N., \& Wolrath Söderberg, M. (2021). Knowledge Fear and Conscience: Reasons to Stop Flying Because of Climate Change. Urban Planning, 6(2), 314-324. https://doi.org/10.17645/up.v6i2.3974

Wynes, S., Donner, S. D., Tannason, S., \& Nabors, N. (2019). Academic air travel has a limited influence on professional success. Journal of Cleaner Production, 226, 959-967. https://doi.org/10.1016/j.jclepro.2019.04.109

Žagar, I. (2010). Topoi in critical discourse analysis. Lodz Papers in Pragmatics, 6(1), 3-26. https://doi.org/10.2478/v10016-010-0002-1 
Open Access This chapter is licensed under the terms of the Creative Commons Attribution 4.0 International License (http://creativecommons.org/licenses/ by/4.0/), which permits use, sharing, adaptation, distribution and reproduction in any medium or format, as long as you give appropriate credit to the original author(s) and the source, provide a link to the Creative Commons licence and indicate if changes were made.

The images or other third party material in this chapter are included in the chapter's Creative Commons license, unless indicated otherwise in a credit line to the material. If material is not included in the chapter's Creative Commons licence and your intended use is not permitted by statutory regulation or exceeds the permitted use, you will need to obtain permission directly from the copyright holder.

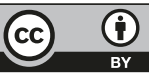

